\title{
Intermedial Translation as Circulation
}

\section{Chu Tien-wen, Taiwan New Cinema, and Taiwan Literature}

\author{
Jessica Siu-yin Yeung \\ soAs University of London, London, UK \\ jessica_yeung@soas.ac.uk
}

\begin{abstract}
We generally believe that literature first circulates nationally and then scales up through translation and reception at an international level. In contrast, I argue that Taiwan literature first attained international acclaim through intermedial translation during the New Cinema period (1982-90) and was only then subsequently recognized nationally. These intermedial translations included not only adaptations of literature for film, but also collaborations between authors who acted as screenwriters and filmmakers. The films resulting from these collaborations repositioned Taiwan as a multilingual, multicultural and democratic nation. These shifts in media facilitated the circulation of these new narratives. Filmmakers could circumvent censorship at home and reach international audiences at Western film festivals. The international success ensured the wide circulation of these narratives in Taiwan.
\end{abstract}

\section{Keywords}

Taiwan - screenplay - film - allegory - cultural policy

\section{Introduction}

We normally think of literature as circulating beyond the context in which it is written when it obtains national renown, which subsequently leads to international recognition through translation. In this article, I argue that the contemporary Taiwanese writer, Chu Tien-wen (b. 1956)'s short stories and screenplays first attained international acclaim through the mode of intermedial translation during the New Cinema period (1982-90) before they gained recognition 
as works of literature on the national level. I define intermedial translation as the adaptation of a literary work into another medium - in this case from fiction or screenplay to film. I am particularly interested in the cross-medial products that resulted from the collaboration between filmmakers and authors who acted as screenwriters. I consider these kinds of intermedial collaborations to be the precursors of the use of multimedia and new media by writers such as Chen Li who creates audio-visual poems. Kuei-fen Chiu has recently called this "a new worlding model of world literature" that has opened up "a new horizon of networked literary production and dissemination" (14) in the late print era.

The collaborative work of writers and filmmakers occurred in one of the most intense periods of Taiwan's nation-building and has accelerated the process described by Pascale Casanova as the emergence of a "small literature" (248). Casanova describes this as a two-step process that begins with the invention of a national literary tradition followed by individual authors seeking autonomy from national politics in literary works that combine the new national literary tradition with aesthetic elements that have garnered international critical acclaim. In Taiwan, these two steps happened concurrently as writers and filmmakers collaborated during the period of Taiwan New Cinema.

Taiwan's status as a small nation is justified by its "layered colonialism" (Shih, "What Is Sinophone Studies?" 12) by the Dutch (1624-1662), Spanish (16261642), Japanese (1895-1945), and Chinese (1662-1683, 1683-1895, 1945-). Taiwan's relationship with the United States as a de facto protectorate (Shih, "Theory" 730) complicates the island's colonial history. In the anti-communist Cold War era, Taiwan sided with the United States. Taiwan, then under the Nationalist regime, was forced out of the United Nations in 1971. In 1978, the United States established official diplomatic relations with Communist China, which further marginalized Taiwan on the international stage (Hong 82).

In the wake of this decision, an intense discussion began among literary figures in Taiwan and beyond over whether Taiwan literature ${ }^{1}$ should be regarded as part of Chinese literature or as a separate literary tradition (Tang 382 ). This dovetailed with a new focus of literary works and films emerging in the $1980 \mathrm{os}$

1 According to Huang Mei-E, "Taiwan literature" is used to refer to "all literature produced on the island of Taiwan; works not written [in Taiwan] may also be included if they are related to Taiwan". The term is different from "Taiwanese literature," which only includes "the oral tradition (folktales [...] passed down by word of mouth) and classical and modern literature". Due to the multilingual and multicultural nature of Chu Tien-wen's literary works, "Taiwan literature" and "Taiwan cinema" are used in this article. Taiyu (the Taiwanese language) is only one of the languages being spoken in her literary works. 
on the reality of multicultural and multilingual Taiwan. These narratives question the ideology of Taiwan as the "free China" that the Kuomintang (кмт), the authoritarian party defeated by the Chinese Communist Party during the Chinese Civil War (1927-37, 1945-49) which retreated to Taiwan in 1949, imposed during their rule.

While literary studies have discussed the many cinematic adaptations of literary works set in this period, they have not yet grasped their importance for the emergence and international recognition of certain contemporary figures in Taiwan literature. Such an approach has to take into account that many authors acted as screenwriters and thus transposed their narratives directly into film. Literary histories usually do not discuss these films. ${ }^{2}$ I argue that they are essential to understanding how these authors and screenwriters in contemporary Taiwan literature gained recognition. Like many classic literary works published in the 1980s, they promoted a new vision of Taiwan as a small but multilingual, multicultural, and democratic nation, as I will explain in the second part of my paper. However, Taiwan filmmakers could circumvent domestic censorship more easily than writers were able to. An important narrative means in this process was allegorical storytelling. Moreover, films attracted more international attention than literary works. The most important example of this is A City of Sadness which won the Golden Lion Award at the Venice Film Festival. In the fourth section, I will explain how later governments after the end of Martial Law in 1987 have tried to maintain the international visibility of Taiwanese film and, subsequently, literature by funding their international distribution. The authors involved in the New Cinema period have also won national and international literary prizes. Cinema

What has come to be known as Taiwan New Cinema is a period of filmmaking in the 198 os that is closely intertwined with the simultaneous emergence of a new literature. During this time, twenty fictional works of Taiwan literature were adapted into films (Taipei Golden Horse, "Film Synopsis" 129-71). Among these were works by Taiwanese nativist, modernist, feminist, and neo-nativist writers which produced a diverse modern Taiwanese corpus (Chen 9). Some of

2 Literary histories are usually confined to discussions on fiction, poetry, drama, and prose. See Chen Fang-ming's A History of Modern Taiwanese Literature. 
the most prominent writers were Huang Chunming, Wu Jin-fa (nativists); Pai Hsien-yung, Chi Teng Sheng (modernists); Li Ang, Liao Hui-ying, Hsiao Sa (feminists); and Chu Tien-wen and her younger sister, Chu Tien-hsin (neo-nativists). Huang's "Sandwich Man" and Wu's Spring and Autumn Tea House were later made into films with the same title in 1983 and 1988 respectively, bringing to light nativist themes about the shock of modernity for Taiwanese villagers. Pai's Jade Love and Chi Teng Sheng's "The Matrimony," which were respectively made into films in 1984 and 1985 tell modernist stories of incest, alienation, comingof-age, and failed romance. Feminist writers produced works such as Li's The Butcher's Wife which was adapted into Woman of Wrath (1984) while Liao's Ah Fei was made into a film in 1983 . Hsiao Sa's Kuei-Mei, A Woman was adapted into a film in 1985. Her "Hanson My Son" and "This Love of Mine" were adapted in 1986 and "The Farewell Coast" was made into a film in 1987.

In addition, many writers acted as screenwriters in this period. However, as Deborah Sang has pointed out, literary scholars have not paid attention to this important development when discussing the relationship between Taiwan literature, intermedial translation, and Taiwan cinema because most analyses focus on "adaptations from fiction into film; very few talk about the relationship between screenplays and film" (152, my translation). Citing Douglas Garret Winston's The Screenplay as Literature (151), Sang argues that some screenplays can be seen as literature (151), especially those that are published. Moreover, in her discussion about the most well-known screenwriter of this period, Chu Tien-wen, she argues that her long collaboration with the filmmaker Hou Hsiao-hsien is what intermedial translation is about. Sang sees screenplay as a "source text" for film narrative, "but without the function to decide on the direction that the narrative takes" (152, my translation). Rather than decisively influencing the films, Chu's screenplays functioned as a blueprint for the actors and the technical staff, because Hou already knows the gist of the film and often improvises on the set (Hou and Chu 689; Chu, "Those" 74). These collaborations between writers adapting fiction into films characterize the New Cinema period as one that produced films where writers, screenwriters, and filmmakers showcased their different strengths while working on a specific screenplay. These films are therefore not only relevant for the history of film, but also for the history of literature in Taiwan.

Chu Tien-wen represents the postwar generation of baby-boomer writers in Taiwan. Her father, Chu Hsi-ning, was a Chinese anti-communist writer, her mother, Liu Mu-sha, a Taiwanese translator of Japanese literature. Although she was a leading proponent of linking Taiwan literature to Chinese literature during the 1980s, her literary works became more critical of the км тovernment and its ideology when she began to collaborate with filmmakers involved 
with the New Cinema: "Episodes that implicitly undermine the Nationalist government's political myth or criticize inherent problems in the present system began to appear in her screenplays and in her fiction" (Y. Chang 66). Chu wrote compelling stories about the failed romances of urban-dwellers and the marriage between waixengren (Mainland Chinese migrants moved to Taiwan after 1940s) and bengxengren (Taiwanese) to convey themes of coming-of-age, thereby interweaving their personal memories, national history, and Taiwanese encounters of modernity in postwar Taiwan. As such, her fiction combines concerns about local Taiwanese life as seen in the work of nativist writers (Huang and $\mathrm{Wu}$ ) and the psychological themes explored by modernist writers (Pai and Chi Teng Sheng). Her works produce a kind of neo-nativist literature and film that is at once local and modern. It is this particular mixture that Casanova describes as important for the international recognition of small literatures. In Chu's case, the international recognition comes about through intermedial translation into film.

Several of Chu's short stories were adapted for film during the New Cinema period. "Growing Up" (1982), "My Favorite Season" (1983), and "Eden No More" (1982) were made into Growing Up (1983), My Favorite Season (1985), and Drifters (1985). These three films are respectively about the coming-of-age of a village boy, a fake marriage becoming a real one, and the enduring friendship between three friends. Chu, however, became far more important as a screenwriter. Following her debut with Growing Up to A City of Sadness (Hou Hsiaohsien, 1989), she wrote or co-wrote twelve screenplays (Taipei Golden Horse, "Film Synopsis" 129-71) during the New Cinema Period. Several of her screenplays were also published as books, including Record of the Moving Clouds (2015), which is the screenplay of The Assassin (Hou Hsiao-hsien, 2015). She cowrote this screenplay with her niece Hsieh Hai-Meng, Hou Hsiao-hsien, and Zhong Acheng. Apart from this, she also published seven screenplays that she wrote or co-wrote for Hou. ${ }^{3}$ In total, Chu wrote or co-wrote twenty-one screenplays within thirty-four years between 1982 and 2015. Chu's collaboration with directors resulted in films that described a new nation that was multilingual, multicultural, and democratic and thereby stood in contrast to the official ideology of the кмт. The first way she did this was to stress multilingualism, hence moving beyond the Mandarin-only policy. The кMT promoted Mandarin Chinese as the official language of Taiwan, banned the use of Japanese, and

3 These are Dust in the Wind (film, 1986; screenplay, 1987), A City of Sadness (1989; 1989), The Puppetmaster (1993; 1993), Good Men, Good Women (1995; 1995), Millennium Mambo (2001; 2001), Café Lumière (2003; 2006), and Three Times (2005; 2006). 
strictly limited the use of other dialects (Hong 63). These policies oppressed Taiwan's multicultural and multilingual communities which include approximately 2.37 percent of indigenous peoples and over 95 percent of Han Chinese from mainland China who had been coming to Taiwan since the seventeenth century, including the Hakka and Hoklo groups (International Work Group for Indigenous Affairs; Shih, "Linking" 223). These people speak a mix of "Mandarin, Hakka, and Hoklo," as well as "a variety of Austronesian languages" (Shih, "Sinophone Studies" 12). It is this polyphony and multilingualism which defines "Taiwan [as] a major site of Sinophone literature" (Shih, "Sinophone Studies" 13).

How important Chu's writing was for moving beyond official monolingualism becomes clear when we look at her story "Growing Up" that was turned into a film in 1983. The story does not present Taiwan as a Mandarin-Chinese speaking country, but as multilingual. The mainlander father, Mr. Bi speaks Mandarin Chinese and the Taiwanese mother, Hsiu-ying converses in a mix of Taiwanese and Mandarin. The film preserves the linguistic difference or the multilingualism of Mandarin and Taiwanese between the couple. Literature thus contributes to creating the new vision of a multilingual Taiwan circulating in film in the New Taiwan Cinema period.

This also holds true for A City of Sadness. The screenplay, co-written by $\mathrm{Chu}$, not only contains the features of multilingualism and multiculturalism, but also expresses a critical stance towards the regime. The film is a historical epic about Taiwanese history between 1945 and 1948 after the Japanese had retreated from the island and the кмт had begun to establish its rule (Hou "Interview" 116; Jones 179). The film retells the national trauma of the 228 Incident, the KMT crackdown of the anti-government protests on 28 February 1947:

The February 28th Incident (1947) began with a crackdown by the Taipei City Monopoly Bureau on a forty-year-old widow allegedly selling contraband cigarettes. A conflict broke out between the bureau investigators and the vendor, Lin Chiang-mai, which incited a series of violent, island[] wide confrontations between Taiwanese natives and the recently arrived Nationalists. The incident eventually escalated into a widespread bloody purge of Taiwanese intellectuals and political leaders.

HOU and CHU 716 note 12

Within a week after the quarrel between the widow and the KMT soldiers took place, the кмт police and army killed more than 10,000 anti-government protesters. The majority were intellectuals and communists (Assayas 215). The film retells this historical episode through the fate of the Lin family. It empha- 
sizes the experience of the youngest brother, who is deaf and mute, and his wife, who are both ordinary, marginalized civilians. The film represents Taiwan as a nation under authoritarian rule struggling to make progress toward democracy. The multilingualism, multiculturalism, and democratic progress on display in this film criticize the кмт rule as authoritarian and monolingual (Mandarin Chinese). The international and national circulation of these critical narratives was facilitated through intermedial translation, which arose from the collaborations between writers and filmmakers.

The Taiwan New Cinema period was a time when many young directors set up their own film companies so they could exercise greater creative freedom. These directors are Hou Hsiao-hsien, Edward Yang, Chen Kun-hou, Chang Yi, Wang Tung, Wan Jen, Ko Yi-cheng, Tseng Chuang-hsiang, Lee You-ning, and Mia Ta-chieh. They came up with ideas for films that speak to people's lives in postwar Taiwan, drawing parallels between personal memories and national history, coming-of-age, urban romance, and mainlanders' experiences in Taiwan. Hou, Yang, and Chen also worked as screenwriters themselves and worked with writers such as Chu Tien-wen, Wu Nien-jen, Ding Yah-ming, and Hsu Shuchen to adapt Taiwan fiction into film. Some of the directors in this group such as Hou and Chen formed their own production companies for making films that are close to daily life to resonate with the audience. They were all operating within the linguistic, cultural, economic, and political limitations in the Martial Law period, but some attempted to broaden the circulation of their films to a wider audience.

During the New Cinema period, circumventing censorship was easier to do by making films than it was writing fiction. Taiwan in the early 1980 s was a period when "all creative works seemed to be censored" as Wu Nien-jen, Chu's co-screenwriter of three films, commented in the documentary $H$ HH: Portrait of Hou Hsiao-Hsien (Olivier Assayas, 1997). "Movies seem to be a better medium" than literature for voicing opposition against the authoritarian regime through arts, he said (Assayas, $H H H$ ). "During the white terror [between 1949 and 1987] when Taiwanese society was closed, all kinds of repression built up and was released with the coming of New Taiwan Cinema," said Chu's longtime collaborator and director, Hou Hsiao-hsien, echoing Wu in an interview (Hou and Chu 687). Due to its offer of greater latitude and political and creative freedom under Martial Law, film became a popular medium of choice for Taiwan's culture industry. 
Early films such as Growing Up were successful in Taiwan. The film won awards for Best Picture, Best Director, and Best Screenplay Adaptation at the Golden Horse Film Festival in Taiwan. However, the filmmakers were not satisfied with only succeeding in the national field, and instead set their sights on the international arena. Chu wrote or co-wrote twelve screenplays in this period. ${ }^{4}$ Although no other film beside A City of Sadness won a top prize like the Golden Lion, they reflect Taiwanese screenwriters' and directors' initial attempts to achieve international recognition by competing in and winning prizes in mid-tier and major film festivals after screening their films on the national level. These efforts to upscale would later allow these filmmakers to take even more liberties and circumvent censorship even more successfully in A City of Sadness.

The Boys from Fengkuei (1983), A Summer at Grandpa's (1983), A Time to Live, A Time to Die (1986), and Daughter of the Nile (1987) established Taiwan's international reputation as a mid-tier player to contend with before 1989. The Boys from Fengkuei won the Golden Montgolfiere, the top prize in the mid-tier Three Continents Festival in Nantes in 1984. The film transforms Hou's teenage experience into a story of four boys who leave their fishing village in Fengkuei to make a living in the second biggest city in Taiwan, Kaohsiung. A Summer at Grandpa's draws upon Chu's childhood memories of staying at her grandpa's house in rural Miaoli during the summer to tell the story of two young, middle-class siblings, who spend a summer in the countryside, meet some local children and immerse themselves in nature before they return to Taipei. This film won the Jury Prize at Locarno in Switzerland in 1985 and the Golden Montgolfiere at the Nantes Three Continents Festival in 1985. A Time to Live, A Time to Die also draws on Hou's childhood memories of his move from mainland China to Taiwan when the KMT pushed back against the Chinese Communist Party during the Cold War. This film was the first time Taiwan competed in top-tier international film festival and it won the FIPRESCI Prize in Berlin International Film Festival in 1986. Daughter of the Nile likewise competed in the Cannes Film Festival in 1988, although it did not win any prize. These films won awards in mid-tier film festivals and entered major film festivals after being screened in Taiwan, but they did not achieve international success like A City of Sadness, which was screened in Venice, Toronto, and New York and won the Golden

4 A full list includes Growing Up, The Boys from Fengkuei (1983), A Summer at Grandpa's (1984), Out of the Blue (1984), My Favorite Season (1985), The Matrimony (1985), Taipei Story (1985), A Time to Live, A Time to Die (1985), Dust in the Wind (1986), Drifters (1986), Daughter of the Nile (1987), and A City of Sadness. 
Lion before returning to Taiwan. Each time Taiwan filmmakers entered and successfully competed in a more prominent level of film festivals, it gave them the confidence to aim even higher which eventually led to A City of Sadness winning the Golden Lion in 1989.

Winning the Golden Lion enabled Taiwan cinema to attain recognition in the international film circuit, which in turn had repercussions on how Taiwan literature was valued. Taiwan also became recognized as a democratizing nation. According to Liao Ping-hui, one of the reasons the film received the accolades it did was because it celebrated Taiwan's "gradual development toward democracy" as the кмт lifted Martial Law (294). Not only did Taiwan want to be seen this way on the international geopolitical stage, but the West was also a willing, waiting audience, despite pressure from the PRC. Others celebrated the telling of this story for the first time. Until the film was first released in Toronto and then in Venice in September 1989 (Chu, "Inspiration" 86) before it opened in Taiwan in October 1989, "the difficult reality behind the evolution of a Taiwanese national identity that was inherently unique and culturally separate from the plight of mainland Chinese in the latter half of the 2oth century was not a subject that was easily discussed or emotionally accepted" (Acquarello, emphasized in the original). Using the political allegory of the Lin family's story to allude to Taiwanese national history and identity (Jameson 69) would remain a staple of Taiwan literature long after this film attained international renown in world cinema.

Critics responded equivocally to A City of Sadness upon its initial release in Taiwan where it was considered to be a menace to the кмт government. During the editing of the film, the massacre in Tiananmen Square occurred in the PRC. "European film festival audiences made the comparison [between Taiwan's 228 Incident and PRC's Tiananmen's massacre] so often that the Taiwanese government news agency became quite unsettled" (Yip 28o note 8). As a result, the film was censored. "Government censors initially cut a scene depicting KM T soldiers tracking down and shooting Taiwanese patriots in their mountain hideaways from the domestic version of the film" (Yip 28o note 4). However, as the film was internationally recognized, the pathway for its downscaling and more favorable reception in Taiwan was paved. Due to Hou's "well-publicized protests over the cuts, the scene was restored" (Yip 28o note 4). In December 1989, it was "a shock to many," however that the state-sponsored Golden Horse Film Festival in Taiwan awarded "The Best Feature Film" to a Hong Kong film, Full Moon in New York (Stanley Kwan, 1989). People were disappointed that A City of Sadness lost at the Golden Horse Film Festival after "the upsurge of national pride generated by the Venice award and the tremendous box-office success achieved by the film in Taiwan" (Reynaud 8). 
Apart from its international acclaim, it is the film's allegorical structure that prevented it from being banned in Taiwan. Because the film tells the narrative of the nation through the fate of the Lin family, Chu and Hou could downplay its political content. According to Liao, Hou "openly denied - at least in Taipei that the film was about the February 28 Incident. Both he and his screenwriter [Chu] claimed that the film was about men and women living under the law of nature. Was their explanation an act of self-censorship or a confession?" (291) The allegorical nature of the film privileges interpretation, thereby allowing $\mathrm{Chu}$ and Hou to evade sensitive questions and offer an apolitical reading of the film.

Instead of treating Hou and Chu's response as self-censorship, I see their response as a strategy to downplay the film's political message even further so it could be circulated in Taiwan. Chu emphasized the film's humanism and human agency in overcoming historical upheavals by referring to the representation of "man's reactions to historical upheavals" as a concern shared between her, $\mathrm{Hou}$, and $\mathrm{Wu}$ (Chu, "Inspiration" 79, 81, my translation). The tension between the film as a political allegory, the кмт's censorship of the film, and Hou and Chu's downplaying of its political content highlights allegory's function of allowing for multiple interpretations of texts that straddle fictional content and historical representation. Chu, Hou, and Wu's screenwriting of A City of Sadness took advantage of film as a medium enjoying greater creative freedom than literature, particularly after 1983 when film censorship was relaxed (Hou and Chu 687). The screenplay links Taiwanese national memories in the colonized periods with the construction of national identity, therefore anticipating the keen interest in (re)constructing Taiwanese identity through Taiwan literature in the post-Martial Law period.

The intermedial adaptation from fiction to film and from screenplay to fiction underscores the bidirectional exchange between Taiwan literature and film. Chu's short stories "Growing Up," "My Favorite Season," and "Eden No More" were made into films. Reversely, her short stories of The Boys from Fengkuei, A Summer at Grandpa's, and Daughter of the Nile only appeared after the films were made "to promote the film[s]," according to Chu in an interview (Hou and Chu 688).

This tells us something important about scale-shifting. Taiwan literature first circulated nationally in limited circles through film. It then scaled up when these films were shown internationally and won prizes at important film festivals. International recognition later drove forward downscaling when these films were shown again in Taiwan and gained acceptance and acclaim among a broader audience. Taiwan literature also circulates horizontally across different media. Such horizontal circulation takes place across fiction, screenplay, 
and film as Taiwan screenwriters and directors collaborated to adapt fiction into films, write screenplays for films, and rewrite screenplays into fiction. In the next section, I shall focus on the impact that these film adaptations have on government support for film and literature to explore the relationship between government support for Taiwan cinema and for Taiwan literature.

\section{4 Governmental Recognition of Taiwan New Cinema and Literature}

The emphasis on multilingualism in A City of Sadness defied the Mandarinonly policy and its win of the Golden Lion means that this national image of diversity and democracy represents values shared between Taiwan and the West, hence the Taiwanese government can maintain its international visibility by promoting this image through films entered into international film festivals. The Taiwanese government has subsidized film-making through the stateowned corporation, Central Motion Pictures Corporation (CMPC) since 1954. From the outset, the subsidies were overwhelmingly awarded to films made in Mandarin and marginalized Taiwanese-language films. The government went even further in 1958, when it extended support to the making of Taiwaneselanguage films provided that they also be accompanied by Mandarin-dubbed copies (Wang, "Golden Horse"). In 1962, the Government Information Office, which is in charge of government policies related to domestic media, established eighteen awards for "Outstanding Mandarin Films" in the Golden Horse Film Festival. In line with its monolingual policy, only films made or dubbed in Mandarin were eligible for consideration. Altogether, the films supported by government subsidies were very successful. By 1986, at least two-thirds had won awards at both national and mid-tier international film festivals (Wang, "Program"). After A City of Sadness won the Golden Lion, the Taiwanese government introduced the Program of Supporting Funds for Domestic Films to encourage more Taiwan filmmakers to compete internationally and then to return to the domestic market with improved box office results driven forward by their international status (S.L. Chang 33-34). In 1992, the Taiwanese government introduced another incentive for filmmakers to compete in the international film festival circuit - they offered economic support based on the "ranking" of the film festivals (S.L. Chang 35). The aim of these subsidies was to sustain Taiwan's visibility on the international stage and to continue to spread its image as a modern democratic nation.

The government also supports the international circulation of writers. This began with small-scale local programs that provided institutional and publication support to literary organizations. Since autumn 1972, Taiwan's Ministry 
of Culture, Ministry of Foreign Affairs, the National Museum of Taiwan Literature, and Hao Ran Foundation, for instance, have funded the publication of The Taipei Chinese PEN, an English-language quarterly journal publishing contemporary Taiwan literature. More recently, the government introduced several new programs that support various actors central to making Taiwan literature visible in the international literary world. Funding is now available for publishers, translators, bookfair organizers, museum curators, and academics. In 2013, the Ministry of Culture set up the Taipei Rights Workshop, which offers fellowships and workshops for non-Chinese publishers with the chance to network and receive the latest information on the Taiwanese book market. The Ministry of Culture also recently set up an initiative, Books from Taiwan, to provide up to NTD 500,000 for non-Chinese translators to translate Taiwan fiction, non-fiction, picture books, and comics. Its online platform was launched in 2015. The National Museum of Taiwan Literature, moreover, collaborated with Kuei-fen Chiu from National Chung Hsing University to launch a multiyear "virtual museum" project entitled The Taiwan Literature Archives. The Archives provides English and Chinese information on the literary timeline of Taiwan writers such as Pai Hsien-yung, Huang Chunming, and Li Ang, all writers whose books were made into films during the New Cinema period. The Taiwanese government also funds translation projects in collaboration with American publishers such as Cambria Press. Contemporary Taiwanese Women Writers, an anthology of ten short stories, was published in 2018. It includes Chu Tien-wen's "The Story of Hsiao-Pi," another title for the story that was adapted into Growing Up in the New Cinema period.

\section{5 Taiwan Literature as World Literature after the New Cinema Period}

The works of nativist, modernist, feminist, and postwar baby-boomer authors whose writings were adapted into films continue to circulate in the postMartial Law period. These writers who made their names or became more known in the New Cinema period occupy a privileged status in modern Taiwan literature, which also means that their works were some of the first to be translated into foreign languages. After the lifting of Martial Law, postcolonial Taiwan has also witnessed the emergence of new genres such as indigenous literature, feminist literature, queer literature, hypertext literature, ecological literature, and Asian diasporic literatures. Chu Tien-wen continues to be an active player in the Taiwan's literary scene, not only as a screenwriter for Taiwan cinema, but also as a novelist. Notes of a Desolate Man (1994; trans. 1999) won the prestigious local China Times Literary Award in 1994. Its English translation 
won the prominent Chinese literary translator, Howard Goldblatt, the National Translation Award from the American Literary Translators Association in 2000. Like the allegorical structure and the national narrative in A City of Sadness, this novel can also be read as a political allegory of marginalized Taiwan. The protagonist is a gay professor who mourns over the loss of his former partner to AIDS. The publication of this translated novel by the Columbia University Press was co-funded by the Chiang Ching-kuo Foundation and the Taiwan Council for Cultural Affairs, which became the Ministry of Culture in 2012.

In 2015, Chu's short fiction collection, Fin-de-Siècle Splendor (1990), an eponymous short story from which Eva Hung translated into English, won her the Newman Prize for Chinese Literature, thereby completing the littérisation of Taiwan literature. This prize is seen as "the first major American award for Chinese literature" (Chiu 28). Her nominee and member of the judging panel, Margaret Hillenbrand commented, "[I]n recommending Chu's short-story collection Fin-de-Siècle Splendor for the Newman Prize, I am calling particular attention to the place she occupies in modern Chinese-language literature as a superb practitioner of short fiction, arguably that literature's most triumphant genre." Chu has triumphed in the art of the short story since 1982 when she published "Growing Up," which became one of the first films heralding the New Cinema era. By the time that the story's English translation appeared in 2018, Chu had come full circle as a writer who first gained international recognition through film adaptations of her work, only thereafter gaining national recognition in Taiwan.

\section{Conclusion}

In this article, I have surveyed the case of Chu Tien-wen, who collaborated with filmmakers in the New Cinema era, and have shown how she later became one of the cornerstones of contemporary Taiwan literature in the post-Martial Law period. In the New Cinema era, film censorship was more lenient than literary censorship, hence film as a medium afforded greater political and creative freedom for Taiwan writers and filmmakers to record the changing scenes of Taiwanese society after 1949 and to critique their society during the Martial Law period. This was especially true after 1983 , when film censorship was relaxed. The collaborations between writers, screenwriters, and filmmakers also defined this era. They devoted their respective strengths to produce films that have become testimonies of Taiwanese film and literary histories. The use of allegory in fiction and screenplays during this era aided the diffusion of Taiwan literature, because films adapted from allegorical novels, short stories, 
and screenplays were more likely to circumvent local censors and to appeal to international audiences. Since the New Cinema era, allegory has been central to the nation-building project in literature of Taiwan, which is eager to define its national identity against the PRC to the West. With the use of allegorical storytelling, The Boys from Fengkuei, A Summer at Grandpa's, A Time to Live, A Time to Die, and Daughter of the Nile were first screened in Taiwan before establishing early success for Taiwan cinema in mid-tier international film festivals. Their successes prepared for A City of Sadness's win of the Golden Lion in 1989. Once A City of Sadness received international recognition, it was screened nationally. The film seems to be the only one that relied on international success to circulate nationally in this era. With its success in Venice, $A$ City of Sadness is an important milestone in Taiwan cinema and literature for its discussion of the 228 Incident and for helping to introduce the idea of Taiwan as a multilingual, multicultural, and democratizing country. Its screenplay brought universal compassion and human agency to bear on Taiwan cinema, which enhanced its appeal among international audiences and eventually led to more government support for the national film-making industry. For these reasons, it has remained the most critical film of Taiwan to this day.

Adapting fiction and screenplays into film as a way to circulate local literature internationally, as a means for writers to earn extra income, and as a method to save time and energy for directors who need a script is a common industrial practice in film-making, but the collaboration between Chu Tienwen and the New Cinema directors was uncommon given that international recognition preceded national appreciation for her short stories and screenplays. ${ }^{5}$ However, this does not mean that Taiwan is unique in demonstrating this framework of downscaling. Perhaps the closest example of circulating local literature through film to attain international recognition and bringing this status back to the literary origin is the Hong Kong filmmaker Wong Kar-wai's

5 I thank Tom Cunliffe for this point. Two examples of award-winning film adaptation involving upscaling literature from the national to international level are the Japanese filmmaker Akira Kurosawa's Rashomon (Net Life-Gate) (1950) and the Indian filmmaker Satyajit Ray's Aparajito (The Unvanquished) (1956). Rashomon was adapted from two short stories of Ryūnosuke Akutagawa ("In a Grove" (1922) and "Rashomon" (1915)). These two stories were both adapted from the twelfth-century story collection Konjaku Monogatarishū (Anthology of Tales from the Past). "Rashomon" was closely adapted from the original Konjaku story and an American gothic story, Ambrose Bierce's "The Moonlit Road" (1907). Aparajito was based on the Bengali writer Bibhutibhushan Bandyopadhyay's Pather Panchali (Song of the Road) (1929) and its sequel Aparajito (The Unvanquished) (1932). Rashomon won the Golden Lion in Venice during 1951 and the Best Foreign Language Film in the Academy Award in the same year. Aparajito won eleven international awards, including the Golden Lion in Venice during 1957. 
adaptation of the local writer Liu Yichang's short story "Intersection" (1972) into the film In the Mood for Love (2000).

Liu Yichang (1918-2018), a literary editor, publisher, and writer of both popular and modernist fiction, began his editorial work in 1942 and left his editorship in 200o. But he did not get formal recognition, the Medal of Honour, from the Hong Kong Government until 2001, a year after In the Mood for Love entered competition for the Golden Palm in Cannes and won the Best Actor in 2000. Liu's story was first serialized in the local newspaper, Sing Tao Evening News in 1972, published in the local literary magazine Four Seasons in 1975, and got translated into Japanese in the same year. Although the story was translated into English by Nancy Li and published in a Hong Kong-based translation journal Renditions in 1988 and published by two mainland Chinese publishers in 1992 and in 1998 respectively, it did not get republished in Hong Kong in Chinese until 200o. Wong specifically added the Chinese characters' equivalence of "Special thanks go to Liu Yichang" in white words against a red background at the end of his film, making sure the audience knows that Liu was the writer who wrote the original story. After 2000, Liu has been translated more frequently into other languages, and has been decorated with local honours and critical attention in both Hong Kong and abroad (Leung, Kwok, and Wong vii-xi, 22629).

The cases of how Chu Tien-wen and Liu Yi-chang were first recognized as internationally acclaimed screenwriters and writers through award-winning films in the West prior to being seen as representatives of local literary traditions underscores the "import mentality" of readers, critics, and institutions in postcolonial and small nations or regions (Abbas 6). Ackbar Abbas defines this import mentality as a way of seeing culture coming from elsewhere: "from Chinese tradition" or "from the West." (6) "Not that there was nothing going on in cinema, architecture, and writing, it was just not recognized to be culture as such." (6) Such import mentality, despite a slight improvement in Taiwan and Hong Kong nowadays, still holds true. As the Hong Kong writer and poet, Xi Xi (b. 1938) received her 2019 Newman Prize for Chinese Literature for her poetry, the same prize that Chu received in 2015 for her short story, the Hong Kong literary community was jubilant since a local writer obtained recognition in America. This joy that the Hong Kong literary community felt upon receiving this news implies that Anglo-American centrism, like the legacy of the late Pascale Casanova, is very much alive and there is still much decentering work to do. 


\section{Acknowledgements}

I am grateful to Wiebke Sievers, Peggy Levitt, my anonymous reviewers, Christine S. Bellen, Michael Ka-Chi Cheuk, Tom Cunliffe, Elaine Chung, Yue Han, Ting-Ying Lin, Jacob Meister, and Emilie Yueh-Yu Yeh for their help in enabling the writing of this essay.

\section{Works Cited}

Abbas, Ackbar. Hong Kong Culture and the Politics of Disappearance. Minneapolis: University of Minnesota Press, 1997.

Acquarello. Rev. of A City of Sadness. Sensesofcinema.com. Senses of Cinema, May 2003. Web. 29 Aug. 2018.

Assayas, Olivier, et al. Hou Hsiao-hsien. Trans. Lin Chi-Ming, et al. Taipei: Chinese Taipei Film Archive, 200o.

Casanova, Pascale. The World Republic of Letters. Trans. M.B. DeBevoise. Cambridge, Mass. and London: Harvard UP, 2004.

Chang, Shih-lun. "Taiwanese New Cinema and the International Film Festival Approach." Taipei Golden Horse, 2oth Anniversary 21-39.

Chang, Sung-sheng Yvonne. “Chu T'ien-wen and Taiwan's Recent Cultural and Literary Trends." Modern Chinese Literature 6:1/2 (1992), 61-84.

Chen, Fang-ming. Taiwan xin wenxue shi (A History of Modern Taiwanese Literature). Taipei: Linking, 2011.

Chiu, Kuei-fen. "'Worlding' World Literature from the Literary Periphery: Four Taiwanese Models." Modern Chinese Literature and Culture 30:1 (2018), 13-41.

Chu, Tien-wen. "Hao nan hao nu (Good Men, Good Women) (screenplay)." Chu, The Best of Times $75^{-101 .}$

Chu, Tien-wen. Huang ren shouji (Notes of a Desolate Man) (novel). Taipei: Reading Times, 1994.

Chu, Tien-wen. Interview by Chang Jinn Pei. "Cong fei dianying chu lai de lingguang (Inspiration Coming from Places beyond Films)." Ningwang. Shidai: Chuanyue beiqing chengshi ershi nian (Gazing at an Era: Two Decades after A City of Sadness). By Chang. Taipei: Garden City, 2011, 76-95.

Chu, Tien-wen. Interview by Emmanuel Burdeau. "Chu Tien-wen: 'Naxie houxiaoxian zuimei de yingpian ...' (Chu Tien-wen: 'Those Beautiful Films of Hou Hsiao-hsien ...)." Assayas, et al. 74-77.

Chu, Tien-wen. "Kohi jiko (Café Lumière) (screenplay)." Chu, The Best of Times 138-6o.

Chu, Tien-wen. Notes of a Desolate Man (novel). Trans. Howard Goldblatt and Sylvia Lin. New York: Columbia UP, 1999. 
Chu, Tien-wen. Qian xi man bo (Millennium Mambo) (screenplay). Taipei: Rye Field, 2001.

Chu, Tien-wen. Shijimo de huali (Fin-de-Siècle Splendor) (short-story collection). Taipei: Yuan-Liou, 1990.

Chu, Tien-wen. "The Story of Hsiao-Pi (short story)." Contemporary Taiwanese Women Writers: An Anthology. New York: Cambria, 2018, 25-35.

Chu, Tien-wen. Xi meng rensheng (The Puppetmaster) (screenplay). Taipei: Rye Field, 1993.

Chu, Tien-wen. "Xiao bi de gushi (Growing Up) (short story)." Chu, The Collected FilmFiction 9-21.

Chu, Tien-wen. "Yi dian bu zai (Eden No More) (short story)." Zui xiangnian de jijie (My Favorite Season). Taipei: Yuan-Liou, 1995, 15-41.

Chu, Tien-wen. Zhu tianwen dianying xiaoshuoji (The Collected Film-Fiction of Chu Tienwen). Taipei: Yuan-Liou, 1991.

Chu, Tien-wen. "Zui hao de shiguang (Three Times) (screenplay)." Chu, The Best of Times $161-84$.

Chu, Tien-wen. Zui hao de shiguang: Dianying benshi, fen chang juben, yiji suoyou guanyu dianying de, 1982-2006 (The Best of Times: Short Stories, Screenplays, and All about Films, 1982-1996). Taipei: IN K Publishing, 2008.

Chu, Tien-wen. "Zui xiangnian de jijie (My Favorite Season) (short story)." Chu, The Collected Film-Fiction 101-30.

Chu, Tien-wen, and Wu Nien-jen. Beiqing chengshi (A City of Sadness) (screenplay). Taipei: Three-Three, 1989 .

Chu, Tien-wen, and Wu Nien-jen. "Lian lian fengchen (Dust in the Wind) (screenplay)." Taipei: Three-Three, 1992.

Hong, Guo-Juin. Taiwan Cinema: A Contested Nation on Screen. New York: Palgrave Macmillan, 2011.

Hou, Hsiao-hsien. Interview by Emmanuel Burdeau. "Hou Hsiao-hsien fangtan (Interview with Hou Hsiao-hsien).” Assayas, et al., 79-131.

Hou, Hsiao-hsien, and Chu Tien-wen. Interview by Michael Berry. "Words and Images: A Conversation with Hou Hsiao-hsien and Chu Tien-wen." positions: east asia cultures critique 11: 3 (2003), 675-716.

Huang, Mei-E. "Introduction to Taiwanese Literature." Taiwan Culture Portal. Ministry of Culture, 15 Nov. 2016. Web. 26 Sept. 2020.

Hung, Eva. “Fin de Siècle Splendor (1990)." The Columbia Anthology of Modern Chinese Literature. New York: Columbia UP, 1995, 444-67.

Hsieh, Hai-Meng. Xing yun ji: Cike nieyinniang paishe ce lu (Record of the Moving Clouds: Some Notes on the Making of The Assassin). Taipei: INK Publishing, 2015.

International Work Group for Indigenous Affairs (IWGIA). "Indigenous peoples in Taiwan." IWGIA.org, n.d. www.iwgia.org/en/taiwan. 24 Oct. 2018. 
Jameson, Fredric. "Third-World Literature in the Era of Multinational Capitalism." Social Text 15 (1986), 65-88.

Jones, Kent. Rev. of A City of Sadness. Assayas et al. 179-85.

Leung, Ping Kwan, Kwok Kan Tam, and King Fai Wong, eds. Liuyi changyu xianggang xiandai zhuyi (Liu Yichang and Hong Kong Modernism). Hong Kong: Hong Kong Open UP, 2010.

Liao, Ping-hui. "Rewriting Taiwanese National History: The February 28 Incident as Spectacle." Public Culture 5:2 (1993), 281-96.

Liu, Yichang. Dui dao (Intersection). Hong Kong: Huo yi, 2000.

Liu, Yichang. "Intersection.” Trans. Nancy Li. Renditions 29/30 (Spring \& Autumn 1988), 84-101.

Newman Prize for Chinese Literature. "Chu T'ien-Wen Wins 2015 Newman Prize." Ou.edu/cis. College of International Studies, The University of Oklahoma, 19 Sept. 2014. Web. 2 Nov. 2015.

Reynaud, Bérénice. A City of Sadness. London: BFI, 2002.

Sang, Deborah Tze-lan. "Wenzi yu yingxiang zhi jian: Tan Cike nieyinniang de gaibian (Between Words and Images: The Adaptation of The Assassin)." Nieyinniang de qianshijinsheng (The Past Life and the Present Life of The Assassin). Ed. Chen Szu-chi and Chen Hsiang-yin Sasha. Taipei: China Times, 2016, 144-63.

Shih, Shu-mei. "Linking Taiwan Studies with the World." International Journal of Taiwan Studies 1:1 (2018), 209-27. Web. 8 Sept. 2018.

Shih, Shu-mei. "Theory in a Relational World." Comparative Literature Studies 53:4 (2016), $722-46$.

Shih, Shu-mei. Introduction. "What Is Sinophone Studies?" Sinophone Studies: A Critical Reader. New York: Columbia UP, 2013, 1-16.

Taipei Golden Horse Film Festival Executive Committee. 2oth Anniversary of Taiwanese New Cinema. Taipei: Taipei Golden Horse Film Festival Executive Committee, 2003. Taipei Golden Horse Film Festival Executive Committee. "Film Synopsis." 2oth Anniversary 129-71. Taiwan Literature Archives. Twlit.blogspot.com. National Chung Hsing University, 2014. Web. 27 Oct. 2018.

Tang, Xiaobing. "On the Concept of Taiwan Literature." Modern China 25: 4 (1999), 379422.

Wang, Jen. "Jinma jiang (Golden Horse Film Festival)." Nrch.culture.tw. Encyclopedia of Taiwan, 1 Jun. 2010. Web. 2 Sep. 2018.

Wang, Jen. "Guo pian fudao jin (Program of Supporting Fund for Domestic Film)." Encyclopedia of Taiwan, 18 Jan. 2010. Web. 2 Sep. 2018.

Winston, Douglas Garret. The Screenplay as Literature. Rutherford, N.J.: Fairleigh Dickinson UP, 1973 .

Yip, June. Envisioning Taiwan: Fiction, Cinema, and the Nation in the Cultural Imaginary. Durham: Duke UP, 2004. 


\section{Filmography}

Assayas, Olivier. HнH: portrait de Hou Hsiao-hsien (нHн: Portrait of Hou Hsiao-Hsien). France and Taiwan: Doc \& Co, 1996.

Chen, Kun-hou. Liulang shaonian lu (Drifters). Taiwan: Fai Tan Film, 1986.

Chen, Kun-hou. Xiao bi de gushi (Growing Up). Taiwan: Central Motion Pictures and Evergreen, 1983 .

Chen, Kun-hou. Zuixiangnian de jïie (My Favorite Season). Taiwan: Central Motion Pictures, 1985 .

Hou, Hsiao-hsien. Beiqing chengshi ( A City of Sadness). Taiwan: 3-H, 1989.

Hou, Hsiao-hsien. Cike Nie Yinniang (The Assassin). Taiwan, Hong Kong, China: Central Motion Pictures, China Dream Film Culture, Media Asia, Sil-Metropole, SpotFilms, and Zhejiang Huace, 2015.

Hou, Hsiao-hsien. Dong dong de jiaqi (A Summer at Grandpa's). Taiwan: Central Motion Pictures, 1984 .

Hou, Hsiao-hsien. Fenggui lai de ren (The Boys from Fengkuei). Taiwan: Evergreen, 1983. Hou, Hsiao-hsien. Hao nan hao nu (Good Men, Good Women). Taiwan: ${ }_{3} \mathrm{H}$ Films, Shochiku, and Team Okuyama, 1995.

Hou, Hsiao-hsien. Kohi jiko (Café Lumière). Japan and Taiwan: Shochiku, 2003.

Hou, Hsiao-hsien. Lian lian fengchen (Dust in the Wind). Taiwan: Central Motion Pictures, 1986.

Hou, Hsiao-hsien. Niluohe de nuer (Daughter of the Nile). Taiwan: Fu-Film, 1987.

Hou, Hsiao-hsien. Qian xi man bo (Millennium Mambo). Taiwan: $3 \mathrm{H}$, Orly, Paradis, and Sinomovie, 2003.

Hou, Hsiao-hsien. Tongnian wangshi (A Time to Live, A Time to Die). Taiwan: Central Motion Pictures Corporation, 1985.

Hou, Hsiao-hsien. Xi meng rensheng (The Puppetmaster). Taiwan: Era, Nian Dai, Qiu Fusheng, 1993.

Hou, Hsiao-hsien. Zuihao de shiguang (Three Times). Taiwan: ${ }_{3} \mathrm{H}$, Orly, Paradis, and Sinomovie, 2005.

Hou, Hsiao-hsien, Wan Jen, and Tseng Chuang-hsiang. Erzi de da wanou (The Sandwich Man). Taiwan: Central Motion Pictures, 1983.

Kurosawa, Akira. Rashomon. Japan: Daiei, $195^{\circ}$.

Kwan, Stanley. Ren zai niuyue (Full Moon in New York). Hong Kong: Gam Choi Chai Chok Gung Shut (Golden Glory Production), 1989.

Ray, Satyajit. Aparajito (The Unvanquished). India: Angel Digital Private and Epic Productions, 1956.

Wong, Kar-wai. Huayang nianhua (In the Mood for Love). Hong Kong: Jet Tone Films, 2000. 